\title{
Triadic decision making in lexical memory
}

\author{
DONALD HOMA and ROSS SILVER \\ Arizona State University, Tempe, Arizona 85281
}

\begin{abstract}
Word and category recognition was investigated in the context of other stimuli, where the semantic distance relationships among the stimuli were derived from multidimensional scaling. On each trial, three horizontal strings of letters were presented. In the word condition, a positive response was required when the three strings formed three words; in the category condition, a positive response was required when the three strings formed words belonging to the same category. The results indicated that: (a) category decisions take about 150-200 msec longer than do word decisions, (b) word decisions are facilitated by a common categorical membership but semantic distances within the category are relatively unimportant, and (c) within-category semantic distances systematically altered response time for the category condition. It was hypothesized that semantic distance relationships may be sensitized for categorical decisions, but that only large semantic distances function effectively for word decisions.
\end{abstract}

Ever since Sternberg $(1966,1969)$ demonstrated that a memory retrieval process in short-term memory can be inferred by analyzing the latencies obtained from a speeded classification task, a proliferation of reaction time (RT) paradigms has been developed to investigate the storage and retrieval characteristics of long-term memory. A common assumption is that information in long-term memory is structured or organized according to semantic characteristics (Collins \& Quillian, 1972; Kintsch, 1974; Smith, Shoben, \& Rips, 1974). One promising approach for uncovering semantic structure is the use of multidimensional scaling techniques (Kruskal, 1964; Shepard, 1962) with word categories. Once words have been rated, ranked, or categorized according to semantic similarities, the resulting configuration obtained from multidimensional scaling provides information regarding the likely dimensions underlying the similarity judgments and the degree of semantic similarity among the words. In a series of studies, Henley (1969) was able to show that the likely dimensions for the categories of animals were size and ferocity; a third dimension was less obvious to interpret. Using Henley's data, Rumelhart and Abrahamson (1973) demonstrated that word analogies for words within the same category could be accurately solved in accordance with the vector distance separating the initial argument of the analogy.

Although a number of recent studies, using RT as the basic dependent variable, have implicated the importance of semantic information in recognitive processes (Homa, 1973; Naus, Glucksberg, \& Ornstein, 1972) and categorical judgments (Collins \& Quillian, 1969, 1970; Meyer, 1970; Schaeffer \& Wallace, 1970), the interdependence between structure and process for

Requests for reprints should be sent to Donald Homa, Department of Psychology, Arizona State University, Tempe, Arizona 85281. Research was conducted at New College, Sarasota, Florida, where the second author was an undergraduate. multidimensionally scaled material has only recently been investigated (e.g., Rips, Shoben, \& Smith, 1973). The present research investigated the use of semantic distances derived via multidimensional scaling techniques in a lexical decision task employed by Schvaneveldt and Meyer (1973). In their paradigm, subjects had to rapidly judge whether three strings of simultaneously presented letters formed three words (positive) or contained at least one nonword (negative). Their most interesting result centered around the reduced latencies obtained for the three word stimuli where two of the words were associatively related, as judged by association norms (Palermo \& Jenkins, 1964). Two theories were considered to account for the facilitation obtained for this association effect, a location-shifting model and a spreadingexcitation model. A location-shifting model proposes that RTs are reduced for word triads containing associatively related words because the semantic distance is likely to be shorter for these words than for three unrelated words. Thus, retrieval time, as measured by RT, is strictly dependent upon the distance separating the words being processed. The spreadingexcitation model, in contrast, proposes that facilitation is due to a dependence of retrieval operations. When words are associatively related, activation of the initial word in the triad spreads and excites other words in nearby locations in semantic space; the increase in activation at these locations is what is responsible for facilitating retrieval for associatively related words. Although the two models seem quite similar in terms of the predictions they would make, Schvaneveldt and Meyer (1973) were able to separate the two theories by contrasting performance on word triads, where the associatively related pair was either contiguous (AAU or UAA) or separated by an unrelated word (AUA). Support for the spreadingexcitation model was found because RTs did not differ for these two types of triads, although the distance traversed in retrieval would be greater for the associatively separated triad. 
The experiment reported here differed in a number of ways from the Schvaneveldt and Meyer (1973) paradigm: (a) Within-category scaled distances, derived from multidimensional scaling techniques, were used rather than associatively related words; (b) a condition corresponding to three semantically close words was included, a condition not paralleled in the Schvaneveldt and Meyer study; and (c) the decision criteria in one condition were based on whether the letter strings formed three words, while, in a second condition, the decision criteria required that the three letter strings form words from the same category.

By employing scaled distances, the present study also provides some evidence on whether the distances derived from multidimensional scaling techniques have psychological utility for considerations of search and comparison operations. A secondary reason, however, is that the spreadingexcitation model implies an activation that is generated outward and uniformly in all directions from a lexical entry. However, the use of associated words restricts the observation of any potential facilitation to unidirectional considerations. If activation is largely a multidirectional phenomenon, then the use of a multidimensional space should reflect this influence. The use of word and categorical decision criteria was based on the premise that within-category distances may be primed for categorical decisions but not for word decisions, i.e., the distance separating lexical entries may be differentially processed, depending on the task constraints.

An overview of the word relationships employed in the two conditions is shown, in a simplified form, in Figures 1 and 2 . In Figure 1, a hypothetical word category and some of its lexical entries (Words $1,2,2^{\prime}$, 3 , and $3^{\prime}$ ) are indicated. Within this category, a word triad can be formed which consists of either a tightly knit triad $(1,2,3)$ or two isosceles-type triads $\left(1,2^{\prime}\right.$, 3 and $1,2^{\prime}, 3^{\prime}$ ) that have the same side length but different base lengths. Since each of these three relation-

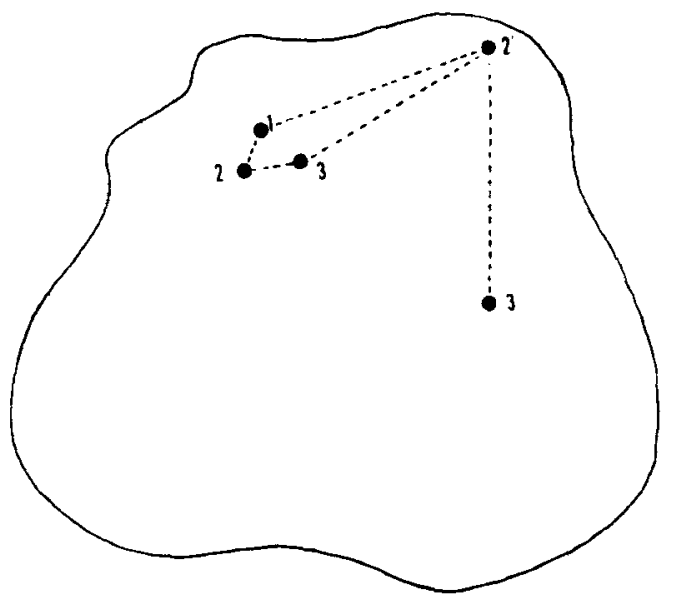

Figure 1. Hypothetical word category with some of its lexical entries.

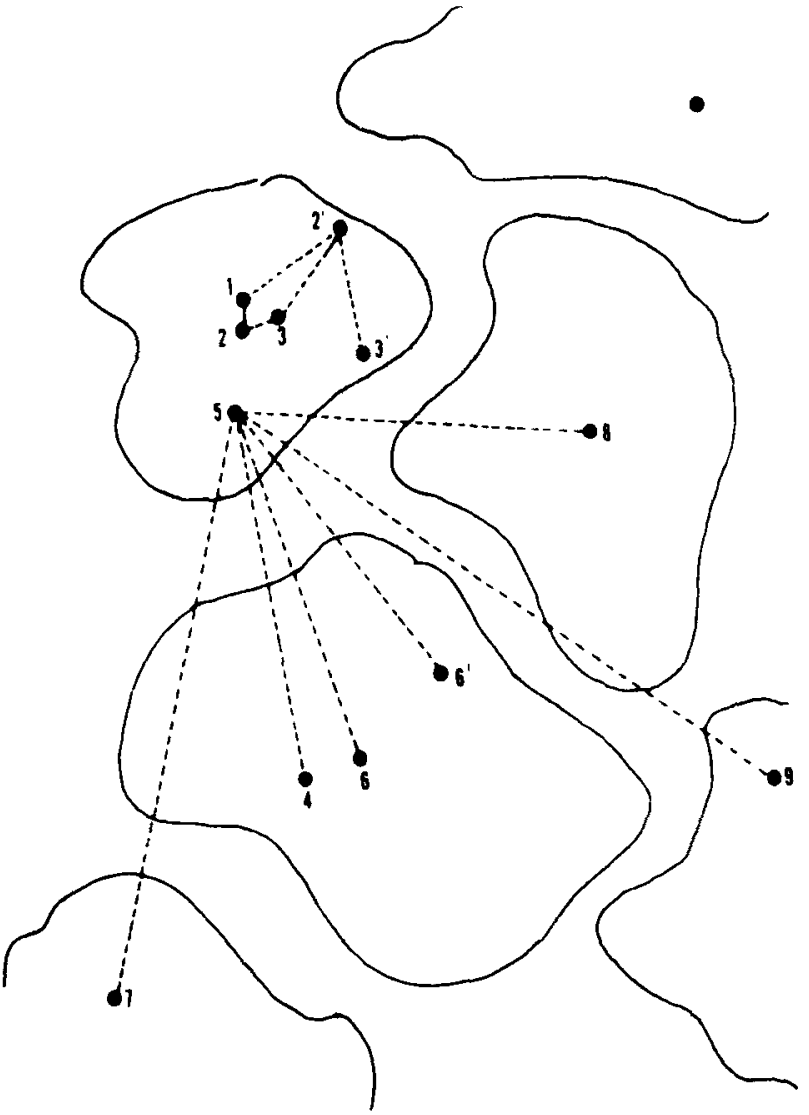

Figure 2. Hypothetical semantic space, showing wond and category relationships.

ships contains words from the same category, a word and a category criterion would necessitate a positive response. For a location-shifting model, which emphasizes the distance traversed as the important variable affecting decision time, the tightly knit triad $(1,2,3)$ should have the smallest RT, and the two isosceles triads $\left(1,2^{\prime}, 3\right.$ and $\left.1,2^{\prime}, 3^{\prime}\right)$ should take longer but not differ from each other if the distance from $2^{\prime}$ to 3 equals $2^{\prime}$ to $3^{\prime}$. For a spreading-excitation model, the predictions would be slightly different since, for the triad $\left(1,2^{\prime}, 3\right)$, activation of the lexical entry located at 1 should be more likely to excite a nearby location, Word 3 , than one further distant, Word 3'. Thus, the spreadingexcitation model would most likely predict that $(1,2,3)$ would be faster than $\left(1,2^{\prime}, 3\right)$, which, in turn, should be faster than $\left(1,2^{\prime}, 3^{\prime}\right)$.

Figure 2 shows some of the other word relations investigated in the experiment, but where within- and between-category triads are indicated. For two of the triads, $(4,5,6)$ and $\left(4,5,6^{\prime}\right)$, the first and third words belong to the same category and the second word belongs to a different category. However, for the triad $(4,5,6)$, the distance separating the first and third words is small, whereas for the other triad $\left(4,5,6^{\prime}\right)$, the base distance is large. Although both of these triads should take longer to process than the three withincategory triads, a spreadingexcitation model again 
predicts that $(4,5,6)$ would be faster than $\left(4,5,6^{\prime}\right)$, while a location-shifting model would predict that latency should be equivalent (since, again, the distances separating the first from the second and the second from the third word is the same for both triads). Finally, a sixth type of triad involving three unrelated words (or three words, each from a different category) is shown, e.g., $(7,5,4)$. For this triad, the two models could make equivalent predictions (that the latency for this triad is longest of all). Note that, for the word decision task, all six of these triad types would require a positive response.

To summarize the predictions for the two models, a location-shifting model would predict that the latencies would be ordered such that

$$
\frac{S}{W_{S} W_{S} W}<\frac{S}{W_{L} W_{L} W}=\frac{L}{W_{L} W_{L} W}<\frac{S}{W U W}=\frac{L}{W U W} \leqslant U U U \text {. }
$$

For the spreadingexcitation model, the predicted ordering would be the same except for the two isosceles-type triads, i.e.,

$$
\frac{S}{W_{S} W_{S} W}<\frac{S}{W_{L} W_{L} W}<\frac{L}{W_{L} W_{L} W}<\frac{S}{W U W}<\frac{L}{W U W}<U U U .
$$

Here, the notation $W_{S}$ refers to two words which are separated by a small within-category semantic distance. $W_{L} W$ refers to two words having a large within-category distance, and $U$ represents unrelated word. The letter over the horizontal bar indicates the within-category semantic distance separating the first and third words of the triad, e.g., L/W UW refers to a three-word triad in which the within-category distance separating the first and third words is large, and the middle word is unrelated [triad $\left(4,5,6^{\prime}\right)$ in Figure 2] .

Negative responses for the word and category decision conditions differ slightly; most obviously, whenever words from different categories are employed, a positive response is required for the word decision task but a negative response is indicated for the category decision task. Other negative triads for both conditions involve the use of nonwords. For the word condition, a negative response can occur only when at least one nonword is contained in the triad. For the word decision task, 6 of the 10 triad types requiring a negative response in volved the use of a single nonword; of these six, two had a nonword in the first position of the triad, two had a nonword in the second position, and two had a nonword in the third position. For each of these pairs, a short and a long within-category distance was again used, e.g., $W_{S} W N$ and $W_{L} W N$ had the nonword located in the third position, but the first triad had two words which differed by a small within-category distance and the second had a long within-category distance separating the first two words. The other four negative triads were $\mathrm{S} / \mathrm{W} \mathrm{NW}, \mathrm{L} / \mathrm{W} \mathrm{N}, \mathrm{N} \mathrm{W}_{\mathrm{S}} \mathrm{W}$, and $\mathrm{N} \mathrm{W}_{\mathrm{L}} \mathrm{W}$. If processing of any triad proceeds from top to bottom, then response time should be directly related to the positioning of the nonword in the triad. For the pairs differing in word distance and having the nonword located in the same position, e.g., $\mathrm{W}_{\mathrm{S}} \mathrm{W} \mathrm{N}$ and $\mathrm{W}_{\mathrm{L}} \mathrm{W} \mathrm{N}$, the predictions are less clear. If distance is the overriding factor, then $\mathrm{W}_{\mathrm{S}} \mathrm{WN}$ should be processed faster than $W_{L} W N$, since the initial two words should be processed faster for the $W_{S} W N$ triad. A complicating factor however, is that response interference could result in that a negative response is warranted for both triads but the initial processing indicates that a positive re sponse is likely.

Triads having two or more nonwords were also used but only for the word condition. To the extent that processing is not strictly serial (or strictly top to bot. tom), the use of two or three nonwords should facilitate a negative response. Table 1 contains a listing of triad types used for the two conditions (omitted are the four triad types for the word condition having two or more nonwords). Table 1 also includes the two euclidear. distance measures relevant to the two models. For the location-shifting model, the critical distance is that separating the first from the second word and the second from the third word, $\left(\mathrm{d}_{12}+\mathrm{d}_{23}\right) / 2$; also relevant for a spreading-excitation model is the semantic distance separating the first from the third word, $d_{13}$. Where indicated, these values specify the average within. category, interword semantic distances for the categories used in the two conditions.

\section{METHOD}

\section{Subjects}

A total of 36 New College students participated in the experiment, 18 in the word condition and 18 in the category condition. A session lasted approximately $1 \mathrm{~h}$.

\section{Materials}

The basic pool of stimulus material was drawn from the categories of weapons, four-footed animals, birds, body parts, and occupations. ${ }^{2}$ These materials had been previously scaled according to MDSCAL analysis by Homa, Hammond, and Gillman (Note 1). For each of these categories, 15 highfrequency category associations were selected from the Battig and Montague (1969) norms and rated for similarity on an 11-point similarity scale by $15-20$ subjects each. (None of the subjects who participated in the earlier scaling phase of these materials was used in the experiment proper.) The resulting similarity matrix was then subjected to MDSCAL analysis for Dimensions I through 5. The two-dimensional representation for each category is shown in Figure 3. For the present experiment, all within-category interword distances were derived from the five dimensional solutions; thus, the two dimensional representations shown in Figure 3 provide a reasonable but not exact indication of the interword relationships actually computed for five dimensions. A rough yardstick of the distances employed can be illustrated with the category birds. Here, canary and pigeon are separated by about 1.00 units, whereas canary and turkey are separated by slightly less than 2.00 units.

For the word condition, a total of 12 different triads were generated for each of the three within-category triad types $\left(S / W_{S} W_{S} W, S / W_{L} W_{L} W, L / W_{L} W_{L} W\right)$, with each of the categories of weapons, four-footed animals, birds, and body parts providing three triads. A corresponding set of 12 different 
Table 1

Stimulus Triad Types Used for Word and Category Conditions

\begin{tabular}{|c|c|c|c|c|c|c|c|c|c|}
\hline \multicolumn{5}{|c|}{ Word Condition } & \multicolumn{5}{|c|}{ Category Condition } \\
\hline $\begin{array}{c}\text { Stimu- } \\
\text { lus } \\
\text { Type } \\
\end{array}$ & Example & $\begin{array}{l}\text { Semantic Dis } \\
\left(d_{12}+d_{23}\right) / 2\end{array}$ & $\begin{array}{c}\text { ance } \\
\mathrm{d}_{13} \\
\end{array}$ & Response & $\begin{array}{c}\text { Stimu- } \\
\text { lus } \\
\text { Type } \\
\end{array}$ & Example & $\begin{array}{l}\text { Semantic Dist } \\
\left(d_{12}+d_{23}\right) / 2\end{array}$ & $\begin{array}{c}\text { ance } \\
\mathrm{d}_{13} \\
\end{array}$ & Response \\
\hline$\frac{S}{V_{S} W_{S} W}$ & $\begin{array}{l}\text { SWORD } \\
\text { DAGGER } \\
\text { SABER }\end{array}$ & .702 & .696 & Positive & $\frac{S}{W_{S} W_{S} W}$ & $\begin{array}{l}\text { SWORD } \\
\text { DAGGER } \\
\text { SABER }\end{array}$ & .808 & .734 & Positive \\
\hline$\frac{S}{V_{L} W_{L} W}$ & $\begin{array}{l}\text { SWORD } \\
\text { BOMB } \\
\text { SABER }\end{array}$ & 1.807 & .696 & Positive & $\frac{s}{W_{L} W_{L} W}$ & $\begin{array}{l}\text { SWORD } \\
\text { BOMB } \\
\text { SABER }\end{array}$ & 1.765 & .734 & Positive \\
\hline$\frac{\mathrm{L}}{N_{\mathrm{L}} \mathrm{W}_{\mathrm{L}} \mathrm{W}}$ & $\begin{array}{l}\text { SWORD } \\
\text { BOMB } \\
\text { WHIP }\end{array}$ & 1.730 & 1.584 & Positive & $\frac{L}{W_{L} W_{L} W}$ & $\begin{array}{l}\text { SWORD } \\
\text { BOMB } \\
\text { WHIP }\end{array}$ & 1.726 & 1.572 & Positive \\
\hline$\frac{S}{N U W}$ & $\begin{array}{l}\text { BOMB } \\
\text { NOSE } \\
\text { CANNON }\end{array}$ & 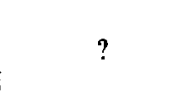 & .694 & Positive & $\mathrm{W}_{\mathbf{S}} \mathrm{W} \mathrm{U}$ & $\begin{array}{l}\text { SWORD } \\
\text { DAGGER } \\
\text { MOUTH }\end{array}$ & $?$ & $?$ & Negative \\
\hline$\frac{L}{W U W}$ & $\begin{array}{l}\text { BOMB } \\
\text { SHEEP } \\
\text { WHIP }\end{array}$ & $?$ & 1.628 & Positive & $\mathrm{W}_{\mathrm{L}} \mathrm{W} \mathrm{U}$ & $\begin{array}{l}\text { SWORD } \\
\text { BOMB } \\
\text { EYE }\end{array}$ & $?$ & $\begin{array}{l}? \\
-\end{array}$ & Negative \\
\hline$J U U$ & $\begin{array}{l}\text { WRITER } \\
\text { DUCK } \\
\text { SPEAR }\end{array}$ & $?$ & $?$ & Positive & $\mathbf{U} \mathbf{U}$ & $\begin{array}{l}\text { WRITER } \\
\text { DUCK } \\
\text { SPEAR }\end{array}$ & $?$ & $?$ & Negative \\
\hline$W_{S} W N$ & $\begin{array}{l}\text { SWORD } \\
\text { DAGGER } \\
\text { TBBER }\end{array}$ & & & Negative & not used & & & & \\
\hline$W_{L} W N$ & $\begin{array}{l}\text { BOMB } \\
\text { KNIFE } \\
\text { DBNNON }\end{array}$ & & & Negative & $W_{L} W N$ & $\begin{array}{l}\text { ARROW } \\
\text { WHIP } \\
\text { EBRT }\end{array}$ & & & Negative \\
\hline$\frac{\mathrm{S}}{\mathrm{WN}}$ & $\begin{array}{l}\text { PISTOL } \\
\text { HVN } \\
\text { RIFLE }\end{array}$ & & & Negative & not used & & & & \\
\hline$\frac{L}{W N W}$ & $\begin{array}{l}\text { SWORD } \\
\text { CPMB } \\
\text { WHIP }\end{array}$ & & & Negative & $\frac{\mathrm{L}}{\mathrm{WNW}}$ & $\begin{array}{l}\text { ARROW } \\
\text { XIIP } \\
\text { CANNON }\end{array}$ & & & Negative \\
\hline $\mathrm{N} \mathrm{W}_{\mathbf{S}} \mathrm{W}$ & $\begin{array}{l}\text { TXORD } \\
\text { DAGGER } \\
\text { SABER }\end{array}$ & & & Negative & not used & & & & \\
\hline $\mathrm{N} \mathrm{W}_{\mathrm{L}} \mathrm{W}$ & $\begin{array}{l}\text { CPMB } \\
\text { KNIFE } \\
\text { CANNON }\end{array}$ & & & Negative & $N w_{L} W$ & $\begin{array}{l}\text { CPMB } \\
\text { KNIFE } \\
\text { CANNON }\end{array}$ & & & Negative \\
\hline
\end{tabular}

triads for the three between-category triad types ( $\mathrm{S} / \mathrm{W} \mathrm{UW}$, $L / W U W, U U U)$ was generated from the within-category sets by substituting a word which distinguished the triads, e.g., for the six triad types of $S / W_{S} W_{S} W, S / W_{L} W_{L} W, L / W_{L} W_{L} W$, S/W UW, L/W UW, and UUU, the triads (PISTOL, GUN, RIFLE), (PISTOL, AXE, RIFLE), (PISTOL, AXE, ARROW), (PISTOL, DUCK, RIFLE), (PISTOL, HEAD, ARROW), and (PISTOL, TAILOR, RAVEN), respectively, were used. This generation procedure reduces the likelihood of idiosyncratic word characteristics differentially affecting the different word triads. In all, a total of 72 different triads were determined (12 from each of the six triad types), each requiring a positive response. A total of 10 different triad types were determined which required a negative response. Of these 10 , six contained a single nonword, three contained two nonwords, and one triad type contained three nonwords. For the six negative triads having a single nonword, two of the triad types had the nonword located in first (top) row, two had the nonword in the second (middle) row, and two had the nonword in the third (bottom) row. For the two triad types having a nonword in the same row, one triad type contained two words which differed by a small within category interword distance, while the other triad type contained two words which differed by a large within-category interword distance; e.g., representative examples of the $W_{S} W N$ and $W_{L} W N$ triads would be, from top to bottom, (HORSE, GOAT, DPW) and (TIGER, MOUSE, XPLF), respectively. Each negative triad was generated from a corresponding positive triad (e.g., HORSE, GOAT, COW); a nonword was formed by incrementing by one letter the first two letters of a word, e.g., COW became DPW, WOLF became XPLF, etc. This generation rule for nonwords equated letter length for words and nonwords while rendering the nonwords unpronounceable. By also including the same words in positive and negative triads, subjects could not key on a particular word to make a positive or negative response. For the three negative triads containing two nonwords, a single word from one of the four categories was randomly selected and positioned in the first, second, or third position of the triad, e.g., $\mathrm{UNN}, \mathrm{NUN}$, and $\mathrm{NNU}$. The single triad type 


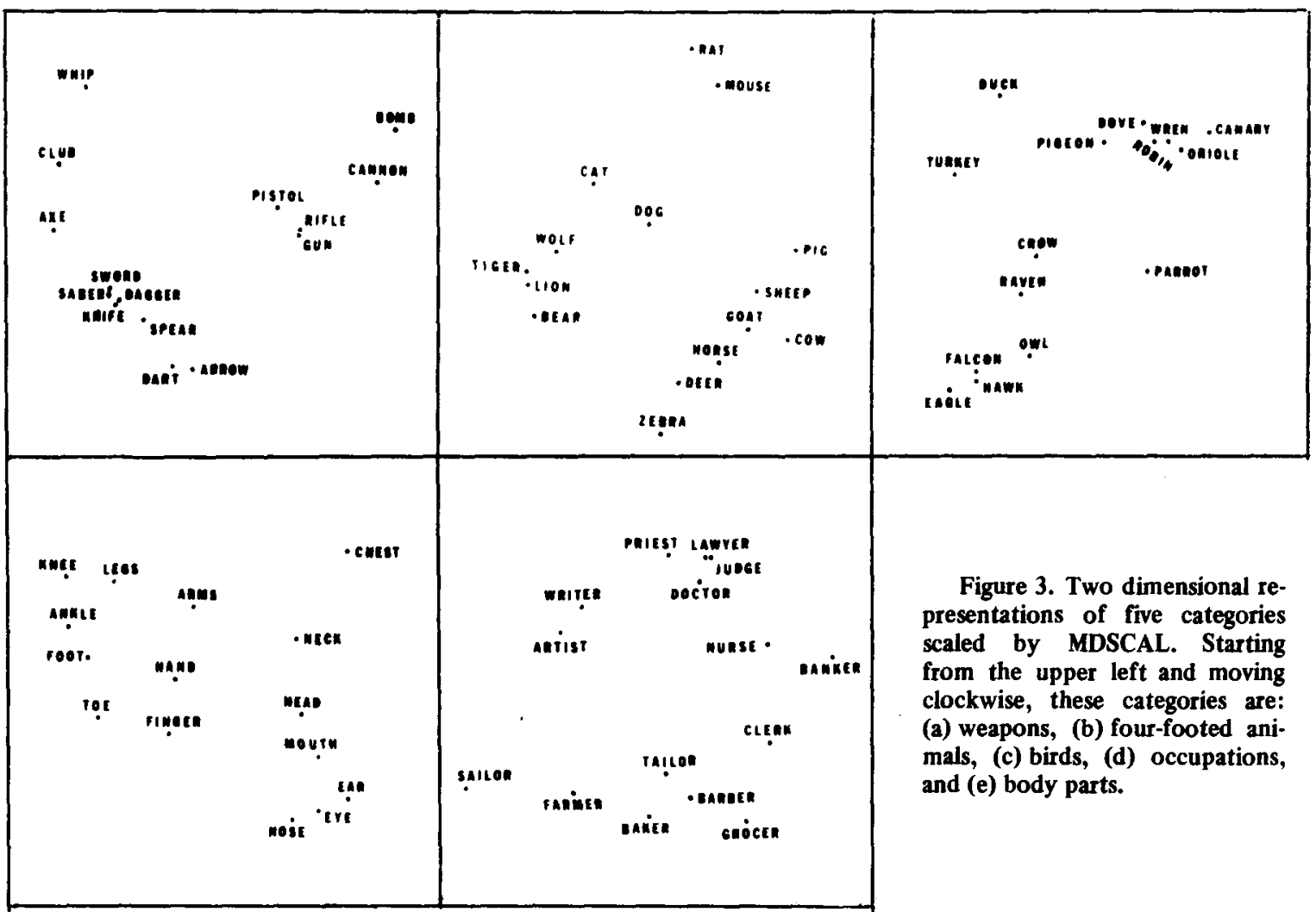

containing three nonwords was determined by taking one of the word triads and applying the incrementing rule. A total of 8 different triads were constructed for each of the 10 negative triad types, making 80 negative triads in all. For the word condition, then, a total of 152 stimulus triads were generated, with a probability of about .47 for a positive response. Across all 152 triads, each word appeared from 1 to 12 times, with an average of about five presentations. Although it was impossible to have each word appear in each of the three rows of a triad, an attempt was made to have each word appear in the same row of a positive and negative triad.

For the category condition, many of the same triads were again employed; however, the total number of triad types was reduced from the 16 used in the word condition to 9 for the category condition. All triads containing two or more nonwords were deleted. Where the word condition had a total of 10 triad types having at least one nonword, only 3 triad types of this sort were used for the category condition: $W_{L} W N$, $\mathrm{L} / \mathrm{W} \mathrm{NW}$, and $N W_{L} W$. The inclusion of these triad types was used to assess a top-to-bottom item processing. Of the remaining six triad types used in the category condition, three triads contained three words, all from the same category (positive), and three contained three words from different categories (negative). The three positive triad types were identical to those employed for the word condition, $S / W_{S} W_{S} W, S / W_{L} W_{L} W$, and $L / W_{L} W_{L} W$; the three negative triads included the $U U U$ triad used for the word condition and two new triad types, $W_{S} W U$ and $W_{L} W U$. The inclusion of the latter two types of triads allowed for an assessment of semantic distance for negative triads in a category task, since the first two words of each triad type belonged to the same category but differed in interword distance.

The total number of stimuli for the category condition was 135,20 triads each for the six triad types containing three words (four each from five categories) and five triads each for the triads having a single nonword. The probability of a positive response was about .44 . Across all 135 triads, each word ap- peared from 1 to 11 times, with an average of about 5 presentations. Fach word appeared in positive and negative triads about equally of ten.

All stimuli were drawn on cards with a LeRoy lettering kit, pen No. 4; letters were $1 \mathrm{~cm}$ high, with approximately $1 \mathrm{~cm}$ separating letter rows of the triad. A three-field tachistoscope (Scientific Prototype, Model GB) was used to present the stimuli; Hunter Klockounters, with timing initiated with stimulus onset and terminated by a response key depression, were used to measure response latencies.

\section{Procedure}

The procedure, with minor exceptions, was identical for the word and category conditions. Each trial was initiated by the presentation of a small fixation point, centered horizontally but positioned slightly above the top row of the triad. The fixation point remained visible for a $2-\mathrm{sec}$ foreperiod. Following offset of the fixation point, a stimulus was presented for $3 \mathrm{sec}$. Each stimulus consisted of three horizontal strings of letters, aligned in a left-hand manner.

For the word condition, each subject was instructed to depress a positive key if the three strings contained three words; otherwise, a negative response was required. For the category condition, a positive response was required if the three letter strings formed not only three words but also three words from the same category. If the stimulus either contained three words from different categories or contained at least one nonword, a negative response was required. Subjects in both conditions were instructed to respond as quickly and accurately as possible.

Subjects in both conditions were also informed of the categories used to generate the triads. It was felt that subjects in the category condition might otherwise respond positively to broad categories such as "living things." Subjects in the word condition were informed of the categories used to generate words, so that they were equated with the category subjects in terms of general prior knowledge of the stimulus materials. 
Stimuli were presented in a randomized manner for each subject; after every three subjects, a different random order of presentation was used. No feedback was provided during the testing session.

\section{RESULTS}

The initial 20 responses were treated as practice and discarded from all subsequent data analyses. For each subject, a mean RT for correct responses was computed for each of the triad types. Figure 4 shows the mean RT for each triad type containing three words, averaged across subjects and shown separately for the word and category conditions.

The most notable results were that: (a) RTs averaged about 150-200 msec longer for categorical than word judgments; (b) within-category interword distances were relatively unimportant for the word condition, but all three within-category triads were faster $(50-60 \mathrm{msec})$ than the three between-category triads; and (c) unlike the word condition, the within-category interword distances were effective in reducing RTs for the category condition.

\section{Word Condition}

An analysis of variance applied only to the six positive triads for the word condition revealed that the main effect of Treatments was highly significant $[F(5,85)=$ $7.20, \mathrm{p}<.001$ ] A Newman-Keuls test (Winer, 1971) indicated that the three within-category triad types did

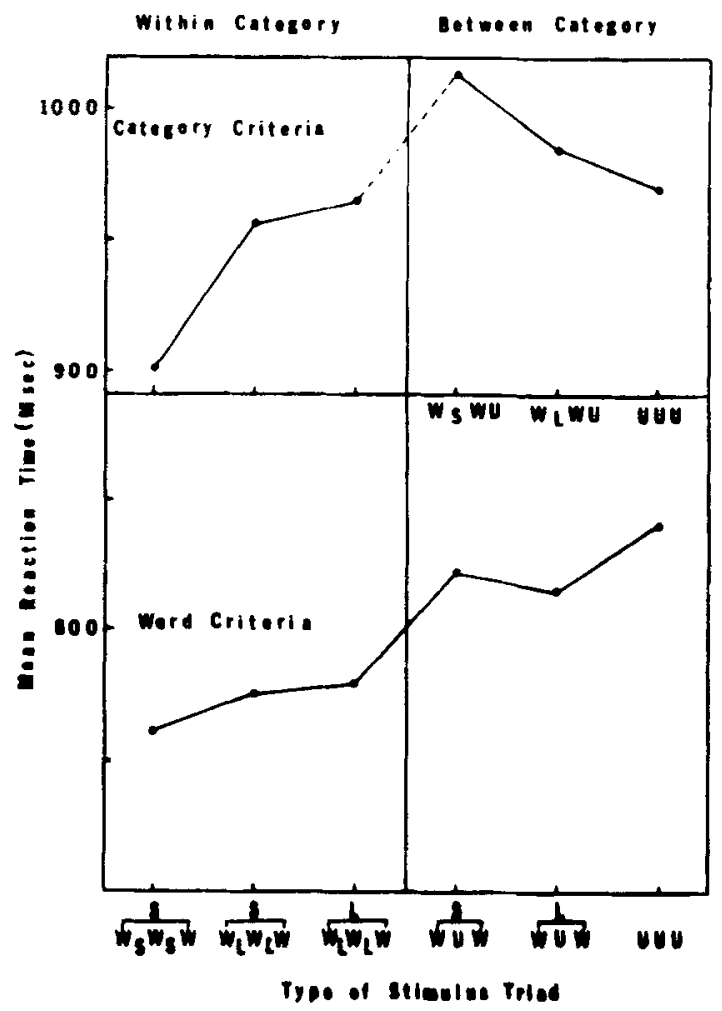

Figure 4. Mean RT for triad types containing three words, shown separately for word and category conditions. not differ from each other, nor did the three betweencategory triad types differ from each other (both ps $>.05)$. However, all three within-category traid types had latencies which differed significantly from the three between-category triad types $(p<.05)$. These latencies, averaged across the three within-category and three between-category triads, were 772 and $826 \mathrm{msec}$, respectively. A closer inspection of individual subject responding also failed to distinguish the three withincategory triads; 9 of the 18 subjects had shorter RTs for the $S / W_{L} W_{L} W$ than the $S / W_{S} W_{S} W$ triads; 8 of the subjects were faster on the $L / W_{L} W_{L} W$ than the $\mathrm{S} / \mathrm{W}_{\mathrm{S}} \mathrm{W}_{\mathrm{S}} \mathrm{W}$ triads.

A comparison of the three within-category triads for each of the four categories revealed that two of the categories (four-footed animals and weapons) had shorter RTs for the $S / W_{L} W_{L} W$ than for the $S / W_{S} W_{S} W$ triads, but this was reversed for the other two categories (birds and body parts). The $\mathrm{S} / \mathrm{W}_{\mathrm{S}} \mathrm{W}_{\mathrm{S}} \mathrm{W}$ triad had shorter RTs relative to the $L / W_{L} W_{L} W$ triads for three of the categories (four-footed animals, birds, and body parts), but the differences for two of these categories was slight (4 and $23 \mathrm{msec}$ ). In summary the effect of withinvs. between-category triad types was highly significant, with RTs reduced for the within-category triads by about 55-60 msec; however, the within-category distances were largely ineffective in distinguishing the three within-category triads.

\section{Category Condition}

For the category condition, the mean RTs for the three positive triads were 902,957 , and $966 \mathrm{msec}$ for the $S / W_{S} W_{S} W, S / W_{L} W_{L} W$, and $L / W_{L} W_{L} W$ triad types, respectively. Pairwise comparisons revealed that the $S / W_{S} W_{S} W$ triad differed significantly from both the $\mathrm{S} / \mathrm{W}_{\mathrm{L}} \mathrm{W}_{\mathrm{L}} \mathrm{W}$ triad $[\mathrm{t}(17)=3.51]$ and the $\mathrm{L} / \mathrm{W}_{\mathrm{L}} \mathrm{W}_{\mathrm{L}} \mathrm{W}$ triad $[\mathrm{t}(17)=4.39, \mathrm{p}<.01$ in each case $]$. The two triads having longer within-category interword distances, $S / W_{L} W_{L} W$ and $L / W_{L} W_{L} W$, did not differ from each other $(t<1)$. Individual subject data supported these conclusions; only 3 of the 18 subjects had shorter RTs for the $S / W_{L} W_{L} W$ triads, and only 2 subjects had shorter $R T s$ for the $L / W_{L} W_{L} W$ triads, relative to the $\mathrm{S} / \mathrm{W}_{\mathrm{S}} \mathrm{W}_{\mathrm{S}} \mathrm{W}$ triads. When these triads were compared for each of the categories, the $S / W_{S} W_{S} W$ triads had shorter RTs than the other two triads in each case; across the categories of animals, weapons, birds, body parts, and occupations, these RT differences averaged $93,57,65$, 30 , and $48 \mathrm{msec}$, respectively. If only the four categories used for the word condition are analyzed, the results are unchanged; overall, the mean RTs were 917, 972, and $968 \mathrm{msec}$ for the triads of $\mathrm{S} / \mathrm{W}_{\mathrm{S}} \mathrm{W}_{\mathrm{S}} \mathrm{W}, \mathrm{S} / \mathrm{W}_{\mathrm{L}} \mathrm{W}_{\mathrm{L}} \mathrm{W}$, and $L / W_{L} W_{L} W$, respectively. Mean $R T$ s for each of the categories averaged between 900 and 1,000 msec. Thus, the RTs for the category condition task supported the hypothesis that within-category interword distances are important in determining the speed of semantic deci- 
sions; however, these same triad types, when incorporated within a word decision task, resulted in RTs that were essentially indistinguishable from each other. ${ }^{2}$

\section{Negative Responses}

Figure 5 shows the mean correct RTs for the negative triads for both the word and category conditions. Evidence for serial processing of the triads can best be gauged from the RTs for those stimuli having a single nonword located in the first, second, or third position. For the word condition, these RTs were 710,780 , and $912 \mathrm{msec}$, respectively; for the category condition, the corresponding RTs were 754,865 , and $1,038 \mathrm{msec}$. For the two triads in the word condition that had the nonword located in the bottom position, i.e., $W_{S} W N$ and $W_{L} W N$, the effect of semantic distance separating the initial two words in each triad was ineffective in influencing RT, 911 and $912 \mathrm{msec}$, respectively. For those triads in the word condition having two or more nonwords, mean RTs were reduced relative to triads having a single nonword. For these triads, the mean RTs were $710,716,656$, and 615 for the triads W N N, NW N, N N W, and N N N, respectively. Although the single nonword data strongly support a serial processing of items, the latency reduction for triads having two or more nonwords would suggest that subjects occasionally began their processing from an intermediate position, e.g., row 2 , or that some capacity for parallel processing of these triads exists.

For the triad types in the category condition which contained words from different categories $\left(W_{S} W U\right.$, $W_{\mathrm{L}} \mathrm{W} U$, and $U \mathrm{U} U$ ), pairwise $t$ tests revealed that mean



Figure 5. Mean RT for negative triads having a single nonword, for both the word and category conditions.
Table 2

Mean RT and Error Rates for Fach Triad Type Under Word and Category Decision Criteria

\begin{tabular}{|c|c|c|c|c|}
\hline \multirow{2}{*}{$\begin{array}{l}\text { Triad } \\
\text { Type }\end{array}$} & \multicolumn{2}{|c|}{ Word } & \multicolumn{2}{|c|}{ Category } \\
\hline & RT & Error & RT & Error \\
\hline$S$ & & & & \\
\hline$\overline{W_{S} W_{S} W}$ & 761 & 3.70 & 902 & 7.78 \\
\hline $\mathrm{S}$ & 775 & 185 & 957 & 722 \\
\hline $\mathrm{W}_{\mathrm{L}} \mathrm{W}_{\mathrm{L}} \mathrm{W}$ & & & & \\
\hline $\mathbf{L}$ & 779 & 185 & 966 & 667 \\
\hline$\overline{W_{L} W_{L} W}$ & 179 & 1.00 & 900 & \\
\hline$S$ & 2ר? & 185 & & \\
\hline $\mathbf{W U W}$ & 022 & 1.00 & & \\
\hline L & 015 & 70 & & \\
\hline$\overline{\mathbf{W U W}}$ & 813 & 2.78 & & \\
\hline U U U & 840 & 2.31 & 970 & 4.44 \\
\hline $\mathrm{W}_{\mathbf{S}} \mathrm{W} \mathbf{U}$ & & & 1013 & 8.61 \\
\hline$W_{L} W U$ & & & 985 & 13.89 \\
\hline$W_{\mathbf{S}} W_{N}$ & 911 & 24.31 & & \\
\hline $\mathrm{W}_{\mathrm{L}} \mathrm{W} \mathrm{N}$ & 912 & 20.83 & 1038 & 13.33 \\
\hline $\mathrm{S}$ & 764 & 778 & & \\
\hline$\overline{\text { W N W }}$ & & & & \\
\hline L & 705 & 556 & 865 & 222 \\
\hline$\overline{\mathbf{W ~ N ~ W}}$ & 192 & & & J.J. \\
\hline $\mathrm{NW}_{\mathbf{S}} \mathrm{W}$ & 699 & 11.11 & & \\
\hline $\mathrm{NW}_{\mathbf{L}} \mathrm{W}$ & 720 & 4.17 & 754 & 2.22 \\
\hline W N N & 710 & 2.08 & & \\
\hline N W N & 716 & 1.39 & & \\
\hline N N W & 656 & .69 & & \\
\hline $\mathbf{N} \mathbf{N}$ & 615 & .69 & & \\
\hline
\end{tabular}

RTs were reduced for the $U U U$ triad relative to the $\mathrm{W}_{S} \mathrm{~W} U$ triads $[\mathrm{t}(17)=2.88, \mathrm{p}<.05]$, but not with the $\mathrm{W}_{\mathrm{L}} \mathrm{W} U$ triads $[\mathrm{t}(17)=1.08, \mathrm{p}>.20]$. Although the $\mathrm{W}_{\mathrm{L}} \mathrm{W} \mathrm{U}$ triad was responded to faster than the $\mathrm{W}_{\mathrm{S}} \mathrm{W} \mathrm{U}$ triad (985 vs. $1,013 \mathrm{msec}$ ), this difference was at best marginally significant $[t(17)=1.47, p<.20]$.

\section{Error Rates}

The mean error rate for all triad types for both the word and category conditions is shown in Table 2 ; the corresponding mean RTs for these triad types is also included. The overall error rate for the word and category conditions was .051 and .079 , respectively. For the word condition, error rates for the six positive triad types averaged between .018 and .037 , with a mean of .024 ; for the negative triads, the mean error rate was .074 . For those negative triads having a nonword located in either the first or second position (or both), error rates tended to be quite low, with an average of .037 . Only when the nonword occurred in the final position were error rates substantial: .243 and .208 for $W_{S} W N$ and $W_{L} W N$, respectively. The high error rates for these two triads would also seem to preclude an adequate comparison of RT differences. 
For the category condition, error rates for the three positive triads ranged between .067 and .078 , with an average of .072 . The three negative triads having two initial categorical words had error rates that were higher than those negative triads having either a nonword or an unrelated word in the first two positions, .119 vs. .033 , respectively.

\section{DISCUSSION}

Although categorical decisions required about 150 . $200 \mathrm{msec}$ longer than word decisions, possibly the most interesting and unexpected result was the interaction between scaled semantic distance and decision criteria. For the condition requiring word decisions, triads containing three words from the same category were responded to faster, by about $55-60 \mathrm{msec}$, than words belonging to different categories; however, withincategory interword distances were relatively unimportant in affecting decision time. By focusing upon the within- vs. between-category comparisons, the patterning of results parallels that found by Schvaneveldt and Meyer (1973). It is worth noting that Schvaneveldt and Meyer never investigated performance for triads composed of three associated words.

For the categorical decision condition, three semantically close words were responded to much faster than the two triad types having longer within-category interword distances. Since this result was not obtained for the word condition, even though the same stimuli were used in both conditions, the question arises whether a common processing component exists for the two tasks or whether a categorical criterion somehow sensitizes categorical relationships. Although a formal model seems premature, it is useful to isolate some of the likely processing stages or operations for the two conditions. One such stage is that each item of the triad is processed serially, in a top-to-bottom manner, where determination of a nonword at any time terminates processing and leads to an immediate negative response. That a serial self-terminating process was operative for both conditions is strongly supported by results showing that location of a nonword systematically determines response time. The major distinction between the word and category conditions may be the inclusion of a category decision component for the category task. If the category comparison process involves the matching of semantic feature information from the three words, then this comparison process could be facilitated by item similarity, i.e., semantic distance. Since the two category triads that had different item relationships, $S / W_{L} W_{L} W$ and $L / W_{L} W_{L} W$, but equivalent interword distances did not differ from each other in terms of response time, it would seem that this category-matching operation is mediated by semantic distance alone and not by semantic activation (Schvaneveldt \& Meyer, 1973). It should not be pre- sumed that categorical information is available only following the processing of all three words; rather, it need only be assumed that information regarding the "wordiness" of a stimulus precedes the availability of more abstract, categorical information (Posner \& Mitchell, 1967). In fact, the shorter latency for the U UU triad relative to the $\mathrm{W}_{\mathrm{S}} \mathrm{U}$ triad under the category condition suggests that category comparisons among items may occur simultaneous with, but slower than, word determination; i.e., categorical information is apparently not utilized only following the identification of all three rows of the triad. Since it is also unlikely that words within a triad are physically refixated following the processing of the last item, it seems useful to characterize the categorical decision task as one involv. ing a memory or buffer component.

If it can be assumed that three words require a minimum of two-word comparisons to determine categorical identity (e.g., for words A, B, and C, comparing $A$ with $B$ and $A$ with $C$ or $B$ with $C$ ), then the maximum reduction in latency due to within-category distance would be on the order of $25.30 \mathrm{msec} /$ comparison. This magnitude may be contrasted with the 150 $200 \mathrm{msec}$ necessary to execute the categorical decision for three words, since word and category decisions differed by about this amount. In effect, the time required to determine categorical information for a given word pair would be about $75.100 \mathrm{msec}$, with about $25-30 \mathrm{msec}$ of this total reducible by interword proximity.

For the word decision task, it would be tempting to conclude that semantic distance is unimportant, since the three within-category triads differed only slightly from each other in response time. However, significant latency differences were obtained for within-category vs. between-category triads. One possibility is that, for word decisions, only large vs. small semantic distances are important, and that the within-category distances manipulated here are simply too small. An unpublished study by Homa, Hammond, and Gillman (Note 1) gives some indication of the relative distances separating words within categories to the distances separating categories. Here, 20 words, drawn from five categories, were scaled according to MDSCAL. The resulting scaled configuration of these 20 words revealed five distinct clusters corresponding to the five categories employed. For this material, the average distance separating the approximate center of each category to the average within-category interword distance was about $5: 1$. Conceivably, the 50 - to $60-\mathrm{msec}$ difference found for the within-category vs. between-category triads for the word decision task reflects the view that only large semantic distances are effective in facilitating word decisions.

Finally, the results of this experiment are more supportive of a location-shifting than a spreadingexcitation model (Schvaneveldt \& Meyer, 1973), al- 
though some results cannot be accommodated within either model. For the word condition, the critical difference between the within-category triads, $\mathrm{S} / \mathrm{W}_{\mathrm{L}} \mathrm{W}_{\mathrm{L}} \mathrm{W}$ and $\mathrm{L} / \mathrm{W}_{\mathrm{L}} \mathrm{W}_{\mathrm{L}} \mathrm{W}$, and the between-category triads, S/W UW and $L / W U W$, never approached statistical significance, and yet a spreading-excitation model would have predicted a difference. Since both critical pairs had the same total semantic distance separating words, support for the location-shifting model is gained. However, the slight superiority of the $\mathrm{S} / \mathrm{W}_{\mathrm{S}} \mathrm{W}_{\mathrm{S}} \mathrm{W}$ to the $\mathrm{S} / \mathrm{W}_{\mathrm{L}} \mathrm{W}_{\mathrm{L}} \mathrm{W}$ and $\mathrm{L} / \mathrm{W}_{\mathrm{L}} \mathrm{W}_{\mathrm{L}} \mathrm{W}$ triads, about $15-20 \mathrm{msec}$, failed to reach statistical significance, although both models would have predicted a facilitation. For the category condition, the relative ordering of the three within-category triads, $S / W_{S} W_{S} W<S / W_{L} W_{L} W=L / W_{L} W_{L} W$, is consistent with predictions of a location-shifting model but not a spreadingexcitation one.

\section{REFERENCE NOTE}

1. Homa, D., Hammond, N.. \& Giliman, C. Multidimensional scaling norms for some categorical data. Unpublished manuscript. New College. 1975.

\section{REFERENCES}

Battig, W. F., \& Montague, W. E. Category norms for verbal items in 56 categories: A replication and extension of the Connecticut category norms. Joumal of Experimental Psychology. 1969. 80(3, Pt. 2).

Collins, A. W., \& Quillian, M. R. Retrieval time from semantic memory. Joumal of Verbal Learning and Verbal behavior, 1969. 8, 240-247.

Collins, A. M., \& Quillian, M. R. Facilitating retrieval from semantic memory: The effect of repeating part of an inference. In A. F. Sanders (Ed.), Attention and performance III. Amsterdam: North-Holland, 1970.

Collins. A. W.. \& Quillian, M. R. How to make a language user. In E. Tulving \& W. Donaldson (Eds.), Organization and memon. New York: Academic Press, 1972.

HENLEY, N. M. A psychological study of the semantics of animal terms. Journal of Verbal Learming and Verbal Behavior. 1969. 8, 176-184.

НомА, D. Organization and long-term memory search. Memory \& Cognition, 1973, 1, 369-379.

KINTSCH. W. The representation of meaning in memory. New York: Wiley, 1974.

KRUSKAL, J. B. Multidimensional scaling by optimizating goodness of fit to a nonmetric hypothesis. Psychometrika, 1964, 29, 1-27.

MEYER, D. E. On the representation and retrieval of stored semantic information. Cognitive Psychology, 1970, 1, 242-300.

Naus, M. J., Glucksberg, S., \& Ornstein, P. A. Taxonomic word categories and memory search. Cognitive Psychology. 1972. 3, 643-654.
PAlermo. D. S., \& Jenkins. J. J. Word association norms: Grade school through college. Minneapolis: University of Minnesota Press, 1964.

Posner, M. I., \& Mitchell, R. F. Chronometric analysis of classification. Psychological Revien:, 1967, 74, 392-409.

Rips, L. J., Shoben. E. J., \& SMIth. E. E. Semantic distance and the verification of semantic relations. Journal of Verbal Learning and Verbal Behavior, 1973, 12, 1-20.

Rumelhart. D. E.. \& Abrahamson, A. A. A model for analogical reasoning. Cognitive Psychology, 1973, 5, 1-28.

SChaEFFER, B.. \& WAllace, R. The comparison of word meanings. Journal of Experimental Psychology, 1970. 86. 144-152.

Schvaneveldt, R. W.. \& Meyer, D. E. Retrieval and comparison processes in semantic memory. In S. Kornblum (Ed.), Attention and pertormance IV. New York: Academic Press, 1973

SHEPARD, R. N. The analysis of proximities: Multidimensional scaling with an unknown distance function: I. Psychometrika, $1962,27,125-140$.

Smith. E. E., Shoben, E. J., \& Rips, L. J. Semantic memory and psychological semantics. In G. H. Bower (Ed.). The psychology of learning and motivation (Vol. 8). New York: Academic Press, 1974.

STERNBERG, S. High-speed scanning in human memory. Science, 1966, 153,652-654.

STERnBERG. S. The discovery of processing stages: Extensions of Donders' method. Acta Psychologica, 1969. 30. 276-315.

WINER, B. J. Statistical principles in experimental design. New York: McGraw-Hill, 1971.

\section{NOTES}

1. The category and word conditions were Experiments II and III of a series of experiments, with the category condition run before the word study. In an earlier study (Experiment I of this series), a word condition involving all five categories was run which resulted in data nearly identical to that reported here; however, the fixation point was located in the center of the triad (row 2) and a top-to-bottom scan could not be assumed. When the word condition reported here was run, other triad conditions were added, and one of the categories (occupations) was dropped, primarily for reasons of efficiency in running time per subject. Since the category condition, when re-analyzed for the four categories used in the word condition, was unaffected, the use of four rather than five categories for the word condition would probably not have altered the patterning of results.

2. Quasi-F ratios, with triads nested within triad types treated as a random factor, essentially replicated the major statistical conclusions. For the word condition, mean RT differences for the within- vs. between-category triads was significant $[F(1,24)=7.27, p<.05]$. For the category condition, the $S / W_{S} W_{S} W$ triad differed significantly from the mean of the $S / W_{L} W_{L} W$ and $L / W_{L} W_{L} W$ triads $\left[F^{i}(1,6)=6.67, p<.05\right]$.

(Received for publication September 8, 1975; revision accepted January $14,1976$. 